\title{
A atualidade de Mário Erbolato para a pesquisa em jornalismo
}

\author{
Gustavo Paulo Zonta ${ }^{1}$ \\ Raquel Ritter Longhi²
}

\section{Resumo}

Este artigo investiga as contribuições de Mário de Lucca Erbolato para os estudos em jornalismo no Brasil. Através da revisão das obras do autor e de bibliografias que falam a respeito de sua vida e suas pesquisas acadêmicas, pretende-se apresentar as considerações teóricas de Erbolato sobre a atividade jornalística brasileira. O autor viveu em uma época de grandes transformações na imprensa nacional e seu trabalho virou referência nas escolas de comunicação e jornalismo do país. Erbolato procurou aprofundar o estudo sobre as notícias e sistematizou didaticamente a sua produção: da captação à edição. Quarenta anos após o lançamento de seu primeiro livro, o autor segue atual para a pesquisa em jornalismo. Está presente em diversos estudos e pesquisas que se debruçam sobre a produção midiática e os fenômenos comunicacionais contemporâneos: nas discussões sobre teoria da notícia e critérios de noticiabilidade, nas investigações a respeito do jornalismo especializado e rotinas produtivas da profissão.

Palavras-chave: Mário Erbolato. Teoria da notícia. Critérios de noticiabilidade.

\section{Abstract}

This article investigates the contributions of Mario de Lucca Erbolato to studies in journalism in Brazil. Through the review of the author's works and bibliographies that speak about his life and his academic research, it is intended to present the theoretical considerations of Erbolato on the Brazilian journalistic activity. The author lived in a time of great transformations in the national press and his work became reference in the schools of communication and journalism of the country.

\footnotetext{
1 Professor do curso de Jornalismo da Universidade do Vale do Itajaí - Univali. Jornalista e Especialista em Fotografia pela Universidade do Vale do Itajaí - Univali. Mestrando do Programa de Pós-Graduação em Jornalismo da Universidade Federal de Santa Catarina. E-mail: gugapzonta@gmail.com

2 Doutora em Comunicação e Semiótica (PUC/SP), Mestre em Comunicação e Informação (UFRGS), Professora no Programa de Pós-Graduação em Jornalismo e Curso de Jornalismo da UFSC. Coordenadora do Grupo de Pesquisa Hipermídia e Linguagem/CNPq e do Núcleo de Estudos e Produção Hipermídia Aplicados ao vJornalismo - Nephi-Jor/UFSC. E-mail: raqlonghi@gmail.com

Revista Pauta Geral-Estudos em Jornalismo, Ponta Grossa v.5, n.2, p.41-57, Jul/Dez 2018.
} 
Erbolato sought to deepen the study on the news and systematized in a didactic way the production of them: from the capture to the edition. Forty years after the launch of his first book, the author follows current for the research in journalism. He is present in several studies and research that deal with media production and contemporary communication phenomena: in the discussions about news theory and newsworthiness criteria, in the investigations regarding specialized journalism and productive routines of the profession.

Keywords: Mário Erbolato. News theory. Newsworthiness criteria.

\section{Introdução}

Uma rápida busca pelo nome de Mário Erbolato nas bases de dados online de estudos acadêmicos nos mostra o quanto o jornalista está presente nas pesquisas em jornalismo no Brasil. São centenas de teses, dissertações e artigos que utilizam suas obras como referência para discutir a produção de notícias e a atuação da mídia contemporânea. Em 2018, completam-se 40 anos do lançamento de seu primeiro livro e, apesar das mudanças tecnológicas, econômicas e sociais nessas décadas, as contribuições para o campo do jornalismo permanecem atuais.

Em um período de raras produções na área da comunicação e do jornalismo, Erbolato avançou nos estudos teóricos da notícia. Buscou identificar suas características, propôs definições, classificações e formas de construção. Elencou valores que transformam os acontecimentos em fato jornalístico e sistematizou de forma didática as etapas produtivas da rotina profissional do jornalista. Além da produção científica, incentivou a profissionalização da atividade no país através de cursos práticos ministrados nas redações de jornais e como professor universitário em uma das primeiras escolas de comunicação social do Brasil.

Este artigo procura investigar as contribuições de Erbolato para os estudos em jornalismo no Brasil. Para isso, retoma sua biografia e trajetória profissional para conhecer suas influências teóricas e práticas. Depois, procura entender o que o autor considera jornalismo a partir de definições apresentadas em seus escritos e, posteriormente, aprofunda os conceitos trabalhados pelo autor no campo da produção de notícias através da revisão de suas obras e de trabalhos que abordem a sua produção.

\section{Vida e obra}

Mário de Lucca Erbolato (1919-1990) nasceu na cidade de Campinas, região Noroeste do estado de São Paulo. Sempre foi um fanático por jornalismo e dedicou Revista Pauta Geral-Estudos em Jornalismo, Ponta Grossa v.5, n.2, p.41-57, Jul/Dez 2018. 
praticamente toda a sua vida à profissão e ao estudo da área, como mostra perfil biobibliográfico feito por Eliana Martins Marcolino com colaboração de Waldemar Luiz Kunsch (BORELLI, 2001, p. 198). Entrou pela primeira vez em uma redação de jornal em 1936, como office boy. Levava aos dois jornais de Campinas na época (Diário do Povo e Correio Popular), e aos correspondentes da imprensa de São Paulo, notícias de uma exposição comemorativa do centenário de nascimento de Carlos Gomes. Erbolato trabalhava no escritório do comissariado que iria promover essa exposição, datilografando os comunicados.

No mesmo ano, 1936, aos 17 anos de idade, iniciou a carreira no jornal Diário do Povo. Ali, viu pela primeira vez como funcionava uma redação de jornal. Naquele tempo, ainda se escrevia a mão. "Parece-me que lá já existiam uma máquina de escrever, disputada, aliás, pelos redatores mais jovens, e, nas outras mesas, tinteiros, mataborrões, além de laudas de papel que não eram como as de hoje (...)", lembrou Erbolato em entrevista concedida a Dario Luís Borelli (2001, p. 187).

Inicialmente, o jovem exercia atividades burocráticas e redigia textos curtos e esporádicos, sem qualquer vínculo empregatício. Logo, o jornalismo passou a fascinar Erbolato, que também recebia o incentivo do pai para seguir na carreira. Dois anos depois, em abril de 1938, foi registrado como empregado do Diário do Povo e passou a ter horário e receber salário. Aprendeu a fazer jornalismo nas atividades práticas da redação. No mesmo ano, foi convidado para exercer o cargo de redator-secretário. Lia e corrigia tudo o que ia para a impressão. Anos depois, passou para a função de redatorresponsável.

Fazer jornalismo na época, em uma cidade do interior de São Paulo com cerca de 80 mil habitantes, era um enorme desafio. As dificuldades para se comunicar (telefonemas interurbanos eram complicados de serem feitos) e para se locomover, estradas precárias, trens que levavam horas para chegar à capital, limitavam a atividade dos profissionais de imprensa. Não havia agências de notícias e só os grandes jornais tinham capacidade para manter correspondentes. A cobertura de acontecimentos nacionais e internacionais era feita a partir da leitura de outros jornais ou pela Agência Nacional, do governo, que transmitia informações por telégrafo.

Além de trabalhar à frente do Diário do Povo, Erbolato também foi correspondente do Estado de São Paulo em Campinas. De 1952 até 1960, trabalhou nos dois veículos simultaneamente. Depois, deixou a redação do Diário e permaneceu no Estado. Neste Revista Pauta Geral-Estudos em Jornalismo, Ponta Grossa v.5, n.2, p.41-57, Jul/Dez 2018. 
período, de 1952 a 1956, cursou o ensino superior na Faculdade de Direito da Pontifícia Universidade Católica de Campinas (PUC-Campinas). Exerceu a profissão de formação acadêmica durante muitos anos, mas nunca deixou de ser jornalista e utilizou parte do conhecimento das leis brasileiras nas obras sobre comunicação que escreveu.

O advogado formado, jornalista autodidata, se transformou em professor e pesquisador. No final de 1969, Erbolato foi convidado pelo reitor da PUC-Campinas, Benedito José Barreto Fonseca, para ministrar aulas de jornalismo no curso de Comunicação Social, que seria criado na instituição. Nos primeiros meses da década de 70, começou a lecionar na universidade onde atuou por 20 anos. Esteve à frente de disciplinas como Jornalismo Comparado, Introdução às Técnicas de Jornalismo Impresso, Radiofônico, Televisivo e Cinematográfico. Também foi coordenador do Departamento de Jornalismo e diretor do Instituto de Artes e Comunicações.

Nesta época, eram raros os livros publicados no Brasil que abordavam temas da comunicação. Por isso, o jornalista utilizou autores estrangeiros para discutir aspectos importantes da profissão. Entre essas referências, estão nomes como os norteamericanos Robert Ezra Park, importante sociólogo da Escola de Chicago ${ }^{3}$, e Fraser Bond, com o clássico Introdução ao jornalismo, de 1959, e europeus como o francês Edgar Morin e o italiano Francesco Fattorello. As principais referências brasileiras de Erbolato em seus estudos na área foram os professores Luiz Beltrão e José Marques de Melo (pioneiros do ensino e da pesquisa jornalística no país). Além de ler suas obras, ele também trocava correspondências com os autores e acabou se aproximando de Marques de Melo. Foi ele quem orientou e incentivou Erbolato a escrever seus primeiros livros sobre jornalismo. "Um dia escrevi uma carta a ele, dizendo que tinha vontade de escrever algum livro didático para estudantes de jornalismo. Ele imediatamente me apoiou, me orientou, pediu que eu fizesse um esboço - quer dizer, foi o meu guia”, contou o jornalista em entrevista a Borelli (2001, p. 194).

As 900 páginas datilografadas que apresentou a Marques de Melo se transformaram em três livros: Técnicas de codificação em jornalismo, prefaciado por José Marques de Melo, publicado em 1978 pela editora Vozes; Jornalismo gráfico, publicado pelas edições Loyola em 1979; e Jornalismo especializado, publicado pela editora Atlas

\footnotetext{
${ }_{3}^{3}$ Grupo de professores e pesquisadores da Universidade de Chicago, fundada na década de 1920 nos EUA, que trouxe uma série de contribuições à sociologia, psicologia social e ciências da comunicação.
} 2018. 
em 1980. Essas três obras abordam as práticas e técnicas utilizadas na produção jornalística na mídia mais conhecida por Mário Erbolato e que tinha mais relevância naquela época: o jornal impresso.

Depois de compartilhar seus conhecimentos sobre a prática jornalística, Erbolato publicou mais três obras: Deontologia da comunicação (editora Vozes, 1982), Comunicação e cotidiano (em colaboração com Júlio César Tadeu Barbosa; editora Papirus, 1984) e Dicionário de propaganda e jornalismo (editora Papirus, 1986). Essas publicações mostram um outro lado dos estudos e pesquisas realizados pelo autor. Aqui, seu olhar sobre a comunicação se apresenta para além da prática do jornalismo e recai sobre temas diversos dos aspectos culturais e comunicacionais do país. O autor ainda deixou inacabado um sétimo livro, que se chamaria Jornalismo: teoria e prática.

Diante dessas obras de Erbolato e do objetivo definido nesse trabalho, investigar as contribuições dele para os estudos em jornalismo no Brasil, será dada prioridade para as discussões, presentes nestes livros, que têm essa temática como foco principal. Nos livros que abordam a comunicação de maneira mais ampla, serão identificadas as passagens e textos que têm como tema central o jornalismo.

\section{Jornalismo para Erbolato}

O que é jornalismo para Mário de Lucca Erbolato? Borelli (2001, p. 186) fez essa pergunta ao professor durante entrevista realizada em abril de 1986. A resposta de Erbolato mostra dois lados de sua relação com o campo: o pessoal, que vê no jornalismo seu propósito de vida, e o pesquisador, em busca de indícios que mostrem algum caminho para entender a essência da atividade. Arte, vocação, ciência, técnica são algumas das palavras utilizadas por ele para tentar definir o que seria jornalismo. $O$ objetivo da profissão, para ele, é servir ao povo, aos interesses do cidadão que não tem quem o defenda e dar publicidade aos progressos feitos pelo homem. "Nada do que se fez, do que se faz e do que se fará no mundo se tornará conhecido se não houver um jornalista para divulgar as descobertas, as experiências, as conclusões, os debates" (Borelli, 2001, p. 186).

Logo depois, Erbolato afirma que "não há uma definição sobre o que seja jornalismo", mas sabe-se de sua importância para combater injustiças, melhorar a qualidade de vida da população e fiscalizar o bem público. "O jornalismo dá impressão de ser uma coisa onipresente e onisciente, ainda que deva ser humilde e jamais se 2018. 
considerar plenamente realizado", aponta o autor (Borelli, 2001, p. 186). Em um de seus artigos publicados no livro Comunicação e cotidiano, em que discute a divulgação de informações científicas nos jornais, o autor faz o mesmo questionamento: o que é jornalismo? Erbolato busca uma resposta em Luiz Beltrão. Ele defende que a atividade consiste na:

Informação de ideias, situações e fatos atuais, interpretados à luz do interesse coletivo e transmitidos periodicamente à sociedade, com o objetivo de difundir conhecimentos e orientar a opinião pública, no sentido de promover o bem comum. (BELTRÃO apud ERBOLATO, 1984, p. 97).

Outra definição apresentada por Erbolato, e que pode nos auxiliar a entender sua visão do jornalismo, está no Dicionário de propaganda e jornalismo. O livro levou anos para ser escrito e foi elaborado a partir da consulta de mais de 73 obras, catorze leis, dois decretos-leis e cinco decretos. Ele também consultou boletins, revistas e jornais. Nessa obra, o significado dado pelo autor à palavra jornalismo é:

Profissão que envolve uma série de atividades que visam levar a informação ao público (leitores de jornais e revistas, ouvintes de rádio e telespectadores). Compreende desde a pesquisa de um fato até a produção e edição do texto, incluindo as ilustrações quando for o caso (ERBOLATO, 1986, p. 196).

Essa definição mais prática do conceito de jornalismo nos ajuda a compreender melhor como Erbolato via o campo. Jornalista autodidata e redator durante quase toda a sua vida profissional, o viés técnico da atividade sempre esteve muito presente nos seus trabalhos. Não por acaso, José Marques de Melo, nos seus estudos sobre a pesquisa em jornalismo no Brasil, inclui Erbolato como um nome fundamental. Melo aponta quatro fases históricas - as correntes ético-social, técnico-editorial, político-ideológica e críticoprofissional, em que Erbolato seria um representante da corrente técnico-editorial da pesquisa em jornalismo no país, "em que a preocupação com a técnica jornalística ocupa grande parte dos estudos na área" (SOUSA, 2009).

Além disso, o ensino do jornalismo nas universidades estava iniciando no país quando Erbolato começou a carreira de professor. Por isso, uma de suas principais preocupações sempre foi a de profissionalizar a atividade e levar aos aspirantes a jornalistas e seus alunos as técnicas e práticas da imprensa nacional daquela época. Se analisarmos sua obra, metade dela é dedicada ao jornalismo enquanto atividade profissional, técnica e prática. São livros que se propõem a ser manuais de jornalismo Revista Pauta Geral-Estudos em Jornalismo, Ponta Grossa v.5, n.2, p.41-57, Jul/Dez 2018. 
para alunos de comunicação e docentes, mas com uma maior profundidade conceitual. Como aponta José Marques de Melo no prefácio do livro Técnicas de codificação em jornalismo, "ao contrário dos primeiros manuais de jornalismo produzidos no país, todos eles fiéis ao espírito e à rotina da nossa imprensa, o livro de Mário Erbolato adota um esquema conceitual próprio da Teoria da Comunicação" (ERBOLATO, 1978, p. 6).

Esta obra, Técnicas de codificação em jornalismo, é também a mais significante da carreira de Erbolato, tendo como base as referências feitas a ela nas pesquisas realizadas no campo desde a sua publicação. Segundo dados do Google Acadêmico ${ }^{4}$ (Scholar Google), os estudos do autor foram utilizados em 1.020 trabalhos acadêmicos, entre livros, artigos, teses, ensaios, dissertações. Técnicas de codificação em jornalismo responde por 701 dessas referências. Entre os principais autores que utilizam Erbolato para debater a produção jornalística, está Adelmo Genro Filho. No livro O segredo da pirâmide: para uma teoria marxista do jornalismo, Adelmo referencia o autor quando discute a relação entre a divulgação de informações e a interpretação e a opinião presentes na produção de notícias.

O estudo da notícia, suas características, definições, classificações, formas de construção, os valores que transformam um acontecimento em fato jornalístico são discussões importantes realizadas por Erbolato e que contribuíram para o estudo do jornalismo no país. Portanto, será preciso aprofundar os conceitos trabalhados pelo autor na sua principal obra para compreender de que forma ele sistematiza o processo de produção de notícias: da captação à edição.

\section{Notícia: da caixa escura à utilidade pública}

Erbolato vê a notícia como matéria-prima do jornalismo. "Comerciar e trabalhar com as notícias constitui a função básica dos jornais. Eles compram e vendem informações" (ERBOLATO, 1978, p. 50). Mas antes de ser vendida, a notícia é selecionada a partir de critérios e construída em uma série de etapas técnicas. $O$ autor compara o jornal a uma caixa escura, pois a estrutura interna e os processos realizados para a elaboração das notícias não podem ser observados por quem está do lado de fora. Entre a recepção e a emissão, as informações são tratadas, preparadas e acondicionadas na caixa escura.

4 O Google Acadêmico é uma base de dados que reúne artigos científicos, teses, livros e jornais de universidades. Disponível em: < https://scholar.google.com.br>. Acesso em: 08/12/2018. 
Apesar de sua importância para o jornalismo, Erbolato acredita que ninguém conseguiu definir notícia de forma satisfatória. O autor faz críticas aos teóricos que "dizem como ela deve ser, e não o que realmente é" (ERBOLATO, 1978, p. 53). Entre as definições, listadas por Johnson e Harris (1973), que classifica como insatisfatórias estão: Notícia é um fato recentemente ocorrido e que interessa aos leitores; Notícia é o relato de um acontecimento publicado por um jornal, com a esperança de, divulgando-o, obter proveito. O próprio jornalista, de alguma forma, procura traçar um conceito:

As notícias são comunicações sobre fatos novos que surgem na luta pela existência do indivíduo e da própria sociedade. A imprensa investe capitais enormes, contrata jornalistas e técnicos dentro de sua área, para a função básica de informar. O noticiário deve ter utilidade pública para os leitores e influenciá-los pessoalmente, mostrando-lhes que devem ter um interesse no assunto divulgado. (ERBOLATO, 1978, p. 52).

Se definir notícia parece uma tarefa impossível para o autor, dizer o que ela deve ser (ato que ele critica em outros teóricos) e algumas de suas características parece um caminho mais viável para compreender a matéria-prima do jornalismo. Erbolato acredita que a notícia deve ser: recente, inédita, verdadeira, objetiva e de interesse público. Recente e inédita porque os leitores querem novidades, buscam saber sobre aquilo que ainda desconhecem. "O público deseja fatos novos e, por isso, a técnica é redigir sobre o que aconteceu ontem ou recentemente" (ERBOLATO, 1978, p. 55). Verdadeira pois o jornalismo trabalha com fatos e não com a ficção, objeto dos romances. Objetiva porque o jornalista deve agir com isenção, honestidade e imparcialidade diante dos acontecimentos e redigir a notícia de forma clara. De interesse público pois as notícias devem despertar o interesse do leitor e provocar discussões na comunidade. A repercussão que pode gerar e a importância para o público vão determinar o tamanho da notícia.

Entre essas características que a notícia deve ter, a mais controvertida para o jornalismo, segundo Erbolato, é a objetividade. Para atingir um dos pontos mais difíceis do discurso jornalístico, o autor acredita que ouvir pessoas bem informadas, dar espaço para o contraditório e publicar opiniões de fontes que expliquem e comentem os fatos sejam caminhos viáveis para uma possível objetividade. Embora, o próprio autor reconheça que existam "limites de objetividade permitidos pela natureza humana" (ERBOLATO, 1978, p. 34). A partir da citação deste debate promovido pelo autor, Genro Filho (1987) problematiza a questão da construção do mito do discurso jornalístico objetivo e imparcial: 
É claro que não se trata do simples "relato" e "descrição" de um fato, dentro de supostos "limites permitidos pela natureza humana", separado da análise e do comentário. Trata-se, sim, de uma nova modalidade de apreensão do real, condicionada pelo advento do capitalismo, mas, sobretudo, pela universalização das relações humanas que ele produziu, na qual os fatos são percebidos e analisados subjetivamente (normalmente de maneira espontânea e automática) e, logo após, reconstruídos no seu aspecto fenomênico. (GENRO FILHO, 1987, p. 33$34)$.

Além da objetividade, outros pontos apontados por Erbolato a respeito do que a notícia deve ser também foram investigados por estudiosos do campo do jornalismo nas últimas décadas, como o conceito de verdade jornalística (GOMES, 2009; GUERRA, 2008).

Depois de buscar uma definição para notícia e elencar algumas características que deve possuir, Erbolato procura discutir os critérios adotados pelo jornalismo para escolher e selecionar um acontecimento para ser transformado em notícia: os critérios de noticiabilidade. Nem tudo o que acontece no mundo se transforma em notícia. $\mathrm{Na}$ verdade, a maior parte dos acontecimentos não são registrados pela mídia. A primeira constatação é a de que os critérios variam de acordo com as empresas jornalísticas e seus públicos. O tratamento dado às informações também irá ser diferente em cada veículo. Diante disso, Erbolato apresenta os seguintes critérios de seleção de notícias:

Proximidade - fatos que ocorrem perto do leitor e a ele ligados;

Marco geográfico - fatos que afetam algum lugar, apesar de não terem acontecido próximo a ele;

Impacto - acontecimentos chocantes ou impressionantes;

Proeminência (ou celebridade) - o que se refere a pessoas importantes;

Aventura e conflito - notícias de assassinatos, conflitos, golpes;

Consequências - ações provocadas por outros fatos que mobilizem as pessoas;

Humor - fatos que entretenham o leitor, que também busca diversão;

Raridade - o que foge da rotina, o extraordinário;

Progresso - melhorias nas condições de vida do leitor em sua cidade;

Sexo e idade - fatos que envolvam sexo, como adultérios, e casos incomuns a respeito de idade, como o casamento entre pessoas de idades muito diferentes;

Interesse pessoal - notícias que afetam de forma individual os leitores; 2018. 
Interesse humano - fatos que narram dramas de pessoas comuns;

Importância - critério adotado pelo editor para selecionar a matéria mais importante, a que terá mais repercussão no público;

Rivalidade - fatos que envolvem rivais, como equipes e jogadores de futebol;

Utilidade - informações de utilidade pública para o leitor;

Política editorial do jornal - veículos dão mais destaque para alguma editoria;

Oportunidade - informações que se tornam relevantes a partir de um gancho;

Dinheiro - fatos que envolvem prêmios ou notícias relacionadas com economia;

Expectativa ou suspense - casos que geram expectativa e suspense ao leitor, ele quer saber se houve alguma solução ou um novo desenrolar dos fatos;

Originalidade - fatos que se aproximam das raridades e coincidências;

Culto de heróis - notícias sobre homens e mulheres considerados heróis;

Descobertas e invenções - novidades sobre avanços científicos, como curas de doenças e outras melhorias para a vida das pessoas;

Repercussão - fatos que causam repercussão, como um brasileiro que é assassinado no exterior e a notícia repercute no Brasil;

Confidência - notícias que envolvem pessoas públicas, como atores e músicos.

A lista feita pelo autor possui 24 valores-notícia que, como alerta ele, não são aceitos pela unanimidade. Estela Marques (2014) faz uma análise dos valores apresentados por Erbolato a partir da leitura de Mauro Wolf e aponta possíveis melhorias para a proposta. Ela acredita que os critérios poderiam ser reduzidos se o autor reunisse os que versam sobre fatores muito semelhantes. Por exemplo, "os critérios proeminência, confidências e culto de heróis poderiam constituir um único critério. Eles se referem a pessoas importantes, que dependem da preferência popular e/ou consideradas heroínas por causa de seus feitos ou ações" (MARQUES, 2014, on-line). Outra questão é a relação entre proximidade, marco geográfico e progresso. Os três critérios versam sobre fatos que acontecem perto do leitor, seja por uma questão geográfica ou cultural. Logo, poderiam ser aglutinados apenas em um critério, proximidade.

Marques (2014) ainda aponta outras possibilidades de aglutinação de critérios que poderiam tornar a lista de Erbolato mais enxuta e ampliar a sua eficiência e aplicabilidade nas pesquisas sobre critérios de noticiabilidade realizadas no campo do jornalismo. Para finalizar, a autora ressalta que os valores-notícias não atuam sozinhos, não são Revista Pauta Geral-Estudos em Jornalismo, Ponta Grossa v.5, n.2, p.41-57, Jul/Dez 2018. 
autossuficientes, mas são parte de um conjunto mais amplo de fatores que influenciam a seleção de acontecimentos que serão transformados em notícias.

Apesar das melhorias possíveis e da limitação dos critérios, é interessante notar que a lista apresentada por Erbolato há 40 anos ainda pode ser aplicada ao jornalismo praticado hoje. O fenômeno das notícias hiperlocais vivido nos últimos anos reforça a importância da proximidade. A proeminência dos personagens, principalmente as celebridades, segue sendo um dos principais fatores que influenciam o noticiário nacional. Há inclusive veículos que só trabalham com este tipo de informação. Fato é que a lista proposta por Erbolato é bastante utilizada em pesquisas no campo e sempre lembrada quando o assunto é a problematização dos critérios de noticiabilidade, como no trabalho realizado por Silva (2005). A autora propõe demarcações para os conceitos de noticiabilidade, seleção e valores-notícias, faz o levantamento de vários valores-notícia e organiza um elenco simplificado com o objetivo de operacionalizar análises de notícias.

\section{Captação, redação e edição}

Selecionado o acontecimento a ser reportado, a notícia entra em uma rotina produtiva. Ela é dividida por Erbolato em três etapas: captação, redação e edição - divisão também adotada por Mauro Wolf (2005, p. 229). A captação é a etapa inicial do processo de construção da notícia. Nessa fase, o jornalista realiza pesquisas sobre o tema abordado e colhe informações, pois, como não consegue estar nos locais onde os fatos acontecem, é preciso conhecer os acontecimentos a partir de entrevistas com pessoas, importantes ou anônimas, que os presenciaram. A segunda fase é a redação, momento em que o repórter organiza o material que captou e passa a construir o texto, narrar os fatos a partir das técnicas de apresentação das informações. A última fase é a edição, quando as notícias são tratadas pelos redatores, de acordo com a ordem de importância, e passam a ser hierarquizadas nos espaços dos veículos.

\section{Captação}

Nessa etapa, Erbolato destaca a importância da entrevista, "gênero jornalístico que requer técnica e capacidade profissional, pois se não for bem conduzida redundará em fracasso" (ERBOLATO, 1978, p. 157). A partir da leitura de autores como Juarez Bahia, Luiz Beltrão e Edgar Morin, o autor classifica as entrevistas sob quatro aspectos: 
1) Como geradoras de matéria jornalística: a) de rotina b) caracterizadas.

De rotina são aquelas que o repórter realiza no dia a dia para reunir elementos sobre os fatos do cotidiano que irá reportar. A partir do exemplo apresentado por Erbolato, presume-se que as fontes entrevistadas não são nomeadas no texto, são citadas apenas de forma genérica no corpo da notícia: "testemunhas contam", "os policiais que presenciaram a ocorrência explicam". As entrevistas caracterizadas apresentam trechos das falas de personagens e suas ideias. Além disso, o entrevistado é nomeado no texto.

2) Quanto aos entrevistados: a) individual b) de grupos (enquete e pesquisa).

A entrevista individual é aquela em que há um entrevistador e um entrevistado. Geralmente, o repórter marca a entrevista com antecedência e fala com a fonte para conseguir informações para sua publicação. As entrevistas de grupo ocorrem quando várias pessoas falam a um ou mais jornalistas. Podem ser enquetes, quando o repórter entrevista muitas pessoas para dar opinião sobre o mesmo assunto, ou de pesquisa, que servem para o jornalista esclarecer o leitor a partir de informações repassadas por especialistas, que podem ser citados nominalmente ou não.

3) Quanto aos entrevistadores: a) pessoal (exclusiva) b) coletiva (conferências de imprensa ou pool).

A entrevista pessoal ou exclusiva acontece quando a fonte ouvida fala apenas para um veículo, por não ter sido localizada pelos outros jornalistas ou por vontade própria. Na coletiva, um ou mais entrevistados falam para diversos jornalistas na mesma ocasião. Os repórteres precisam se organizar para que todos possam realizar perguntas e não haja nenhum tipo de monopólio por parte de algum profissional. As coletivas do tipo conferência de imprensa acontecem quando autoridades reúnem os jornalistas para falar, como no caso dos presidentes da República. Já as coletivas do tipo pool ocorrem quando há muitos jornalistas e não há espaço para todos no local. Assim, um grupo de profissionais é selecionado para ouvir o entrevistado e depois repassar o conteúdo para os colegas.

4) Quanto ao conteúdo: a) informativas b) opinativas c) ilustrativas ou biográficas. 
As informativas permitem que o repórter obtenha o relato de um fato a partir de uma testemunha ou de um participante dos acontecimentos. Assim, consegue elementos para compor sua matéria. As opinativas são realizadas com pessoas que têm autoridade para falar sobre determinado tema. As ilustrativas ou biográficas procuram traçar um perfil de algum personagem importante e de destaque na sociedade.

Além do gênero entrevista, na etapa de captação da rotina produtiva de notícias Erbolato procura classificar também as fontes de informação, em dois grandes grupos: as fixas e as fora de rotina. As fixas são aquelas com as quais o repórter tem contato praticamente todos os dias para produzir o noticiário, geralmente as consideradas oficiais, como Polícias, Prefeituras e Tribunais. As fora de rotina são procuradas excepcionalmente, apenas quando o fato noticiado exigir algum tipo de esclarecimento.

\section{Redação}

Erbolato viveu em um período de grandes transformações na prática do jornalismo no país. A construção das notícias e a linguagem adotada pelos profissionais de imprensa passaram por mudanças radicais. Se no início o tipo de escrita adotado era rebuscado/erudito, com o passar dos anos, o surgimento de técnicas de escrita jornalística baseadas na facilidade de compreensão do leitor tornou os textos cada vez mais acessíveis. A notícia precisava ser fornecida de forma rápida e de fácil assimilação para acompanhar o processo de modernização das cidades. "É preciso convir que o jornal é o livro do povo e, por isso, recomenda-se clareza e simplicidade na escrita, porém nunca em prejuízo da correção" (ERBOLATO, 1978, p. 92).

A notícia no jornalismo moderno é construída a partir de uma linguagem que busca fazer-se entender. Assim, segundo Erbolato, o texto jornalístico deve evitar o excesso de adjetivação, "a fim de que a narrativa seja singela e condensada" e deve evitar "escrever com várias palavras o que puder ser redigido com apenas duas ou três" (ERBOLATO, 1978 , p. 94). O autor apresenta oito diretrizes básicas para quem escreve textos jornalísticos: usar linguagem simples, escrever na ordem direta, empregar poucas palavras em cada oração, dar preferência aos verbos na voz ativa, evitar os adjetivos, selecionar as palavras mais simples e de fácil entendimento, explicar as siglas pouco conhecidas e não ter medo de ser muito simples no que for relatar (ERBOLATO, 1978, p. 105-107). 
Além de buscar sistematizar a linguagem adotada pelo jornalismo, o autor também discute as técnicas de apresentação e organização das notícias. Influenciado pelo estilo da pirâmide invertida, que expõe os fatos principais no primeiro parágrafo do relato, técnica do lead, Erbolato defende que qualquer notícia deve responder as seis perguntas clássicas: Quem? Que? Quando? Onde? Por quê? Como? Que dá origem a fórmula: 3Q $+\mathrm{O}+\mathrm{P}+\mathrm{C}=\mathrm{NA}$ (Notícia Analítica - completa). A partir disso e com base no trabalho de José Marques de Melo, enumera 12 tipos diferentes de leads que podem ser construídos pelo repórter: Simples (refere-se a apenas um fato); Composto (anuncia vários fatos); Integral (Notícia completa - 3Q + O + P + C); Suspense/Dramático (provoca emoção); Flash (introduz uma notícia de forma rápida); Resumo (conta tudo o que ocorreu); Citação (inicia com uma declaração); Contraste (revela fatos antagônicos); Chavão (cita um ditado); Documentário (serve de base histórica); Direto (vai direto aos fatos); Pessoal (fala ao leitor). Erbolato deixa claro que a lista é apenas exemplificativa e os tipos de leads podem variar de acordo com a imaginação do jornalista.

\section{Edição}

A última etapa do processo de produção da notícia é a fase de tratamento do conteúdo produzido para que seja veiculado no formato desejado e no espaço definido de acordo com a sua importância. Segundo Erbolato, essa atividade é sempre bastante intensa pois chegam notícias e informações de forma ininterrupta para a equipe de redatores. Além dos redatores, o autor destaca a figura do editor, responsável por um dos setores (editorias) do veículo e que prevê as matérias que serão publicadas e o espaço que vai utilizar. Diariamente, há reuniões entre editores, editor-geral e a administração para definir a distribuição do espaço para cada seção.

O jornalista que for editar/tratar o texto pode solicitar informações complementares para finalizar a notícia, que serão fornecidas pelos repórteres, e também confirmar datas, nomes, cargos e dados através de pesquisa, para evitar possíveis erros e notícias falsas (chamadas de barrigas). O texto final é enviado para ser organizado no espaço destinado a ele e passa para a fase de composição e impressão (ERBOLATO, 1978, p. 220-221).

Dentro da divisão que existe nos veículos de acordo com os assuntos que são abordados, as editorias, Erbolato apresenta algumas que eram permanentes naquele tempo: Esportes, Interior, Ecologia, Educação, Transportes, Polícia, Artes, Política, Suplementos, Minérios e Saúde; e outras que variavam de acordo com o surgimento de Revista Pauta Geral-Estudos em Jornalismo, Ponta Grossa v.5, n.2, p.41-57, Jul/Dez 2018. 
assuntos importantes: Inundações, Seca, Reforma Constitucional. O autor trabalha de forma específica a questão das editorias na obra Jornalismo especializado, em que discute a cobertura de notícias em áreas como esporte e ciência e a fragmentação informativa nos jornais impressos.

A editorialização/segmentação da produção jornalística a partir de temáticas é uma característica apontada pelo autor, e estudada por outros pesquisadores, como Lage (2005), e que segue presente até hoje, mesmo na produção de conteúdo para o jornalismo online, por exemplo. Essa especialização do conteúdo jornalístico também incentivou o surgimento de produtos midiáticos específicos e direcionados para públicos cada vez mais segmentados.

\section{Considerações finais}

Neste artigo, buscou-se identificar as contribuições de Mário de Lucca Erbolato para os estudos em jornalismo no país. O caminho adotado para reconhecer seu legado teórico foi a revisão de suas obras, de bibliografias que abordassem temas relacionados a sua vida e suas pesquisas acadêmicas e também de autores que o referenciassem em seus estudos. Assim, foi possível apresentar algumas considerações teóricas importantes que Erbolato construiu sobre a atividade jornalística brasileira ao longo dos seus 54 anos de carreira.

Erbolato viveu em uma época de grandes transformações na mídia nacional e na forma de se produzir notícias e participou ativamente do processo de profissionalização da profissão. Foi professor universitário em um período em que os livros sobre comunicação e jornalismo eram escassos e encarou o desafio de realizar pesquisas e estudos na área. Por isso, ocupa um lugar importante no pensamento da comunicação e do jornalismo no Brasil.

Quarenta anos após o lançamento de seu primeiro livro, o autor segue sendo referência nos estudos em comunicação e jornalismo. Erbolato consegue sistematizar didaticamente a produção de notícias, organizar conceitos sobre a linguagem jornalística, aprofundar o estudo da notícia e apresentar regras que auxiliam a compreensão da atividade exercida pelos profissionais de imprensa. Também propõe uma classificação importante para o debate a respeito dos critérios de noticiabilidade e a presença de fatores que influenciam na escolha dos acontecimentos jornalísticos. 
Interessante perceber que os estudos realizados pelo autor permanecem atuais e são aplicados em diversas pesquisas que se debruçam sobre a produção midiática e os fenômenos comunicacionais contemporâneos. Debates a respeito da objetividade e a imparcialidade jornalística, sobre o que deve ou não ser publicado, os limites entre informação e opinião, a influência do jornalismo na construção social da realidade e as fontes de informação presentes no noticiário seguem na pauta de quem busca entender o jornalismo hoje.

Apesar da sua contribuição para a área, cabe ressaltar que são escassos os estudos disponíveis que mergulham a fundo na produção de Erbolato. Há poucas informações disponíveis sobre a sua trajetória de vida pessoal e profissional e poucos trabalhos que discutem profundamente os seus estudos.

\section{Referências}

BORELLI, D. L.; MARCOLINO, E. M. "Mario Erbolato: uma vida dedicada ao jornalismo". In: Comunicação e Sociedade. Revista do Programa de Pós-Graduação em Comunicação Social da Universidade Metodista de São Paulo. v. 23, n. 36, p.183- 202, 2001. Disponível em: <https://www.metodista.br/revistas/revistasmetodista/index.php/CSO/article/download/4260/3962>. Acesso em: 20 jan. 2017.

ERBOLATO, Mário L. Técnicas de codificação em jornalismo. Petrópolis: Vozes, 1978. , Mário L. Jornalismo especializado. São Paulo: Atlas, 1981.

, Mário L. Jornalismo gráfico. São Paulo: Loyola, 1981.

, Mario L. Deontologia da comunicação social. Petrópolis: Vozes, 1982

Campinas:

, Mário L. e BARBOSA, Júlio César T. Comunicação e cotidiano.

Papirus, 1984.

1986.

, Mário L. Dicionário de propaganda e jornalismo. Campinas: Papirus,

, Mário L. Leitura de jornais: como motivar a juventude? In: Intercom Revista Brasileira de Ciências da Comunicação, v. 9, n. 54, p. 47-54, 1986. Disponível em:

<http://www.portcom.intercom.org.br/revistas/index.php/revistaintercom/article/download/1 426/1375>. Acesso em: 22 jan. 2018. 
GENRO FILHO, Adelmo. O segredo da pirâmide: para uma Teoria Marxista do Jornalismo. Porto Alegre: Editora Tchê, 1987.

GOMES, Wilson. Verdade e perspectiva: a questão da verdade e o fato jornalístico. In: Jornalismo, Fatos e Interesse: ensaios de teoria do jornalismo. Florianópolis: Insular, 2009. p. 27-66.

GUERRA, Josenildo. A notícia como "reprodução da realidade". In: 0 Percurso Interpretativo da Produção da Notícia: Verdade e relevância como parâmetro de qualidade jornalística. São Cristóvão: Editora UFS; Aracajú: Fundação Oviêdo Teixeira, 2008.

HARRIS, Julian; JOHNSON, Stanley. EI reportero profesional. México. Trillas, 1973.

LAGE, Nilson. A Reportagem: teoria e técnica de entrevista e pesquisa jornalística. Rio de Janeiro. Record. 2005.

MARQUES, Estela. Os critérios, não tão criteriosos, de Mário Erbolato. Núcleo de Estudos em Jornalismo (NJOR), 2014. Disponível em: $<$ https://nucleojor.wordpress.com/2014/02/17/os-criterios-nao-tao-criteriosos-de-marioerbolato>. Acesso em: 10 jan. 2018.

SILVA, Gislene. Para pensar critérios de noticiabilidade. Estudos em Jornalismo e mídia, v.2, n.1. Florianópolis: Insular, 2005, p.95-106.

SOUSA, Jorge Pedro. Revisitando o pensamento jornalístico de José Marques de Melo. VIII Congresso da LUSOCOM, 2009. Disponível em: $<$ http://jornalistadantonjobim.com.br/admin/template/upload/revisitando_o_pensamento.pd f>. Acesso em: 15 jan. 2018.

WOLF, Mauro. Teorias das comunicações de massa. $2^{a}$ ed. São Paulo: Martins Fontes, 2005.

Recebido em: $11 / 06 / 2018$

Publicado em: 21/12/2018 